\title{
Work in Progress: Analyzing Student Outcomes to Inform First-Year Advis- ing Practices and Policies at Northwestern University's McCormick School of Engineering
}

\section{Dr. Emma Tevaarwerk DeCosta, Northwestern University}

Dr. Tevaarwerk DeCosta works as a dedicated first year adviser at the McCormick School of Engineering, where she advises incoming first year students and teaches courses in freshmen design and materials science.

\section{Dr. J. Alex Birdwell, Northwestern University}

Alex Birdwell is an assistant professor of instruction with the Undergraduate Engineering Office and the Mechanical Engineering department at Northwestern University. His research was conducted at the intersection of robotics and biomechanics in the field of human-machine interactions, and explored novel ways to control robotic prosthetic hands. He is very passionate about student education and currently teaches courses at the undergraduate level that have included manufacturing, design, experimental methods, and thermodynamics. He greatly enjoys advising all levels of undergraduate engineering, but predominantly works with first-year students in his role as a McCormick Advisor. He is the producer for the Lightboard studio, and is currently exploring models for effective online and hybrid teaching models.

\section{Dr. Ken Gentry, Northwestern University}

Ken Gentry is a Senior Lecturer and Adviser working mainly with first-year students. He teaches cornerstone design and courses in the biomedical engineering department.

\section{Prof. Richard Wayne Freeman P.E., Northwestern University}

Prof Richard Freeman is a Clinical Assistant Professor at Northwestern University's McCormick School of Engineering and Applied Science. He is one of four McCormick Advisers responsible for developing and implementing the First Year Advising Model. Prof Freeman has previously taught at The United States Coast Guard Academy, Valparaiso University and Iowa State University. Prof Freeman can be reached at richard.freeman@northwestern.edu

\section{Dr. Alan R. Wolff, Northwestern University}

Alan is Senior IT Director at the school. 


\section{Work in Progress: Analyzing Student Outcomes to Inform First-year Advising Practices \& Policies at Northwestern University’s McCormick School of Engineering}

\section{Introduction}

We are a team of dedicated engineering first-year academic advisers formed four years ago to advise each incoming freshmen class of $\sim 500$ students. This model of advising was entirely new to the School of Engineering at Northwestern, and for the first several years the team's work focused on the consistent implementation of existing advising practices and policies for every first-year student. These advising practices have existed for fifteen to twenty years, and although software for advising students had recently been developed (Freeman, 2016) to track student advising consistency, little has yet been done to determine if these practices still applied well to the current student population, particularly as it relates to students who come in meeting the minimum requirements. We describe in this work-in-progress an initial foray into an analysis of ten years of student outcomes to reveal broad trends in student performance and areas where our advising systems and practices most need revision. In particular, we looked into how student math and science preparation affects student outcomes at Northwestern's McCormick School of Engineering. Ultimately, the goal is to use the data available to first-year advisers to better advise minimally prepared students using data easily available to freshmen advisers.

Robinson (2003) found that there was a strong correlation between advanced math and science courses in high school and success in university engineering courses. Mathematics itself has been the subject of much study related to first-year student outcomes. Researchers have attempted to model students' readiness for engineering programs by looking at high school math coursework and standardized test scores (Tyson 2011, Strayhorn 2014, Veenstra 2009). Calculus is present in the first or second year of most engineering curricula and success in these courses is positively correlated with retention in engineering and higher grades in engineering courses (Brown, 2015). As such, many educators have also looked to change these outcomes with interventions specifically in college mathematics courses (Hieb 2015).

In this work in progress, we first describe our current first-year advising model and curriculum in brief. We then look for any broad trends and changes in student preparation in math and science, which have been shown in existing literature to be important to student success in engineering (Robinson 2003). A deeper dive into existing advising practices, curriculum and student outcomes in mathematics and engineering analysis is then described, along with findings, further work needed, and next steps. 


\section{First-Year Advising Model}

Northwestern's McCormick School of Engineering has five full-time first-year academic advisers who are tasked with advising the incoming class as well as teaching (Freeman, 2016). These advisers work with incoming engineering students, starting the summer before they arrive, and continuing through their first year. The advisers utilize the Advising-asTeaching model and collaborate on advising and mentoring students, facilitated by having colocated offices in a suite. Advisers work with each student to collaboratively determine the student's educational goals and develop a path for her to achieve those goals.

Each adviser's primary objectives are to:

- Each assist 100 first-year students with their major selection and academic planning, then serve as a resource throughout their undergraduate careers;

- Teach three courses per year, particularly those for first-year students (Cornerstone Design, Engineering Problem Solving, and/or Departmental Classes);

- Serve as a resource for students and faculty advisers pertaining to electives, special programs, other degree programs, and more;

- Collaborate with the undergraduate engineering office and peer-advisers to assure all students are well-served across all engineering majors;

- Facilitate training and education to develop effective academic skills within students.

In order to meet these objectives, students are required to have an individual meeting with the advisers each quarter. During these mandatory quarterly meetings advisers review each student's course load and standing, work with the student to suggest improvements for academic skills (e.g. effective study habits and time management), help with major selection, and discuss how a student can balance his academics with personal activities and interests.

Facilitating this process is the Advising System (MAS), which serves as an online degree audit and advising-tools system (Freeman, 2016). MAS contains a copy of each student's course and grade history, electronic degree forms, current degree audit, multi-year study plan, and an electronic messaging system. Students and advisers use these tools to review a student's record and create or update a tailored plan for the student, which requires quarterly approval of the study plan before a student can register for courses. Since students and advisers meet regularly, MAS is a living document--it evolves and grows with the student and her goals.

The advising process runs through the first year, but begins during the summer before students arrive for orientation. Dossier is an additional component within MAS and compiles student's self-reported data, as credit earned has not yet been processed by the Registrar. This data includes AP/IB scores, student's potential major and minor, and scores for math (calculus) placement exams, a chemistry placement exam, and optional language exams. Advisers review 
the results from Dossier and contact each student individually (typically via e-mail, occasionally over the phone) before orientation to initiate the advising process, determine fall quarter classes (a "study plan") and answer initial questions as the student prepares for his college career.

During the year, additional academic information is also provided such as each student's academic record, degree program(s) and audit, course history, and evolving study plan. However, non-academic information is not provided, which may include Pell eligibility, work-study status, financial aid, or health records. Though each student is unique and her success results from many factors, and we recognize that these factors play a role in determining the student's academic path, the advisers deliberately consider only academic preparation in developing their advising model, for which initial data and results are presented in this paper.

\section{First-Year Curriculum}

First-year students will generally combine math, basic science, engineering analysis, design \& communication, and electives to round out their courses. The scheduling concept is called Engineering First, and is designed to prepare students to take courses in their major beginning fall quarter sophomore year. A typical schedule is shown below in Table 1, and consists of engineering analysis, freshmen design and communication, math, and science or elective courses over three quarters. The number of incoming AP or IB credits a student might have could diminish their initial load significantly, particularly as it relates to math and basic science requirements the first year.

\begin{tabular}{|c|c|c|}
\hline Fall & Winter & Spring \\
\hline Engineering Analysis 1 & Engineering Analysis 2 & Engineering Analysis 3 \\
\hline $\begin{array}{r}\text { Design Thinking \& Communication I (Fall or Winter) } \\
\text { OR ELECTIVE }\end{array}$ & Design Thinking \& Communication II \\
\hline Calculus & Calculus & Calculus or elective \\
\hline Science/elective & Science/elective & Science/elective \\
\hline
\end{tabular}

Table 1- Typical First Year Schedules based on Engineering First

"Engineering Analysis" is four-quarter sequence of linear algebra (EA1), statics (EA2), dynamics (EA3), and differential equations (EA4) taught in the context of key engineering applications with Matlab as a computational tool and introduction to computer programming. Design Thinking and Communication (DTC) is a project based design course taken twice during freshmen year, with DTC I taken in the fall or winter, and DTC II taken in the spring. First-year students also take calculus and a basic science course determined largely on their major of 
choice. Below, we look specifically at the math and engineering analysis curricula, advising practices, and related student outcomes.

\section{Student Preparation in Math and Science and Outcomes}

Figure 1 shows the percentage of the freshmen class with varying amounts of incoming math and science credit (Chemistry, Calculus AB, Calculus BC, Physics B, Physics C [Mechanics], Physics C [Electricity and Magnetism], Physics 1, Physics 2, Biology, Environmental Science) for 2006 to 2016, binned into categories from zero to two credits, three to five credits, five to seven credits and seven or more credits. The most notable shift is an increase in the number of students with a higher number of math and science credits over the past two years, which can be seen in the growth of the yellow bars. There is also a small increase in the number of students coming in with at least one credit (up from 77\% in 2006-2007 to 83\% in 2015-2016).

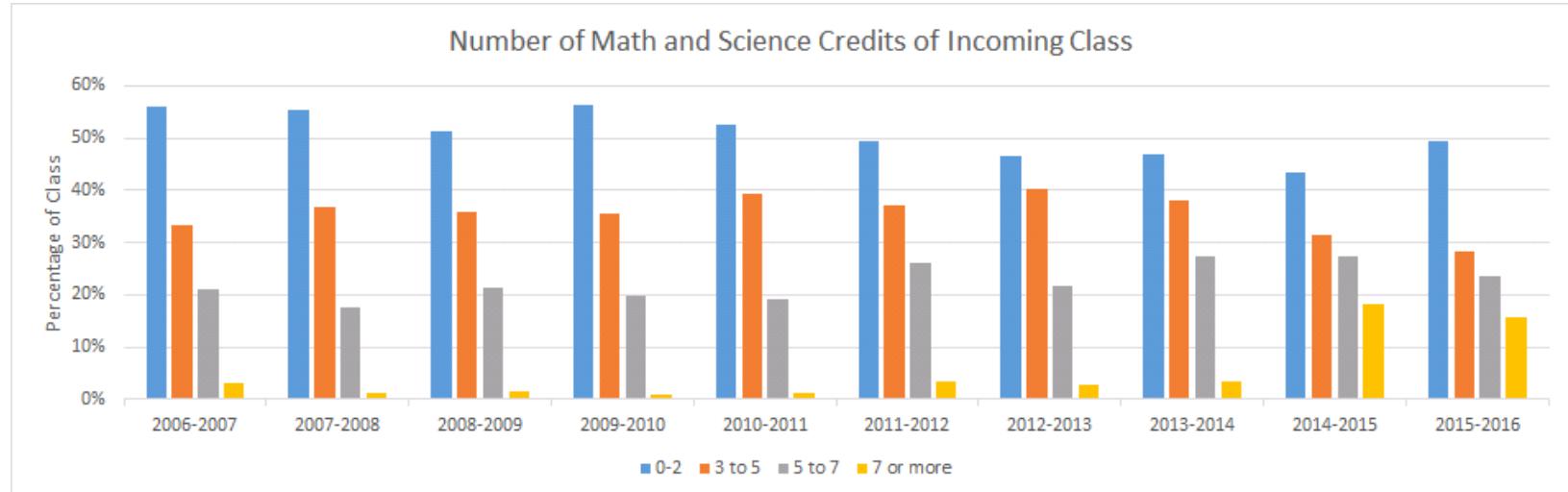

Figure 1 - Percentage of incoming class with 0-2, 3-5, 5-7 and $>7$ credits in math and science from AP/IB/transfer over the last ten years.

The simplest measure of first-year outcomes is the quarterly student GPA from this same data set. In Figure 2, we show the average student GPA and standard error for the last 10 years as a function of the number of incoming math and science credit. There is a direct relationship between the number of math and science credits students enter the McCormick School of Engineering with and their GPA at the end of their quarterly GPA (Figure 2). This suggests that students with less preparation, perhaps because they came from a high school which did not offer AP math or science classes, are very likely to end up at the bottom of their class at the end of the year. This adversely effect on internship opportunities, as many employers now screen out applicants below a certain GPA during the online application process, and can adversely affect graduate school admissions. 


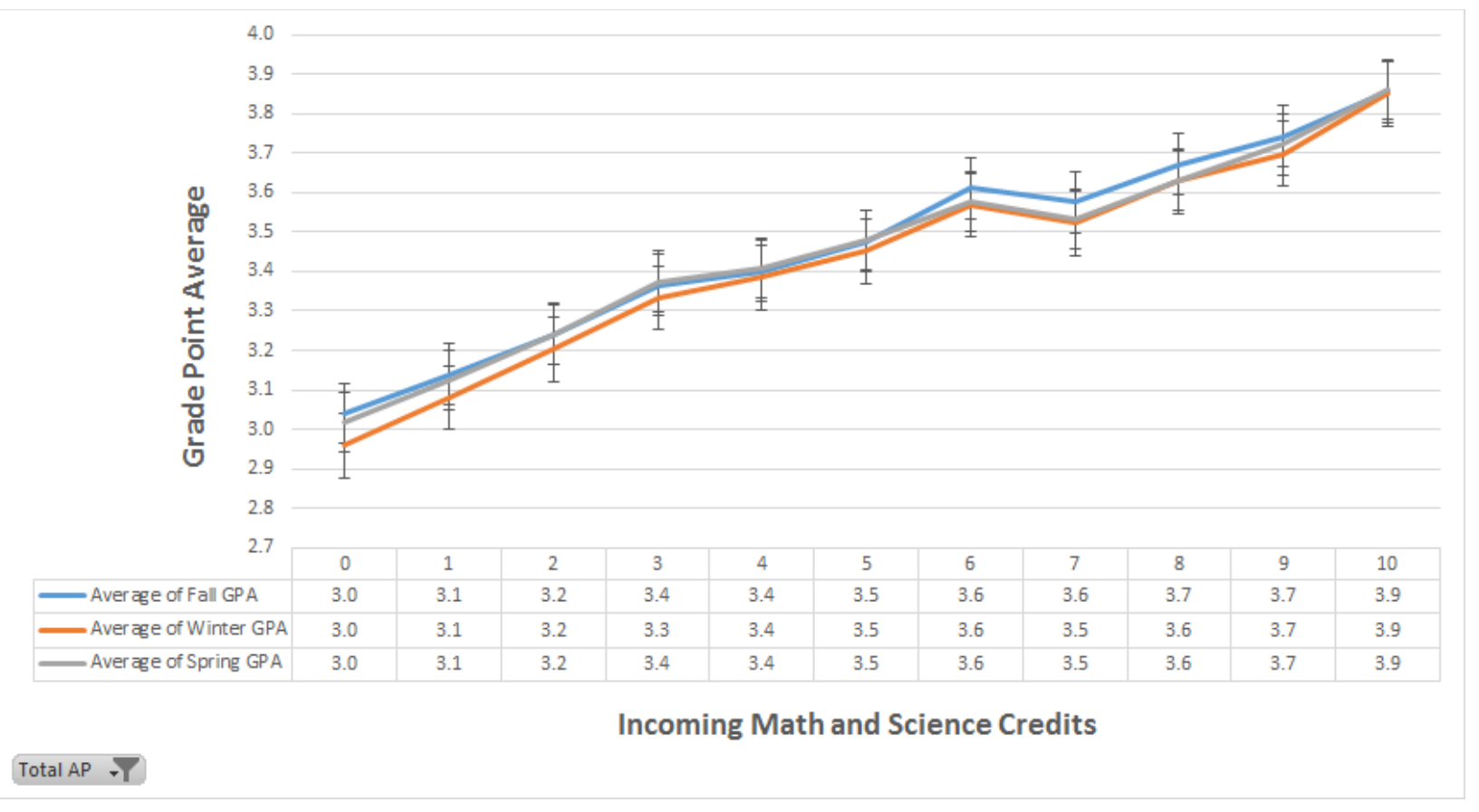

Figure 2 - Average student First-Year GPA (Fall, Winter and Spring) and standard error versus the number of course credits earned from math and science AP exams for 2006-2016

\section{Math Curriculum, Advising Practices \& Student Outcomes}

At most universities, students are placed in their first math course using one of the following two approaches i) AP scores, standardized test scores and high school transcripts or ii) math placement exams administered by the university prior to matriculation. Soulsby (2005) described a unique approach to placement tests, but the majority of institutions use one of the two approaches to math placement described above. While there is a positive correlation between math success and retention in engineering, as noted by Suresh (2006), there is also evidence, noted by Marra (2012), that high school preparation also affects persistence, retention and graduation rates in engineering. Given the impact poor placement can have on students, how placement recommendations are reached are important. Meyer (2014) and Hagg (2007) discuss poor course performance and pre-college preparation as contributing factors to students leaving engineering. There are several publications that address either the validity or validation process of placement tests Zola (2002).

At Northwestern's McCormick School of Engineering, a summer math placement exam is administered by the engineering school to all incoming freshmen over the summer, regardless of their advanced placement or international baccalaureate scores. Results recommend students into one of three course to start their calculus sequence at the University:

- Differential Calculus of One-Variable Functions

- Integral Calculus of One-Variable Functions

- Differential Calculus of Multivariable Functions 
Generally speaking, first-year advisers recommend that students start in the level of math that the placement test suggest, particularly if this result is supported by AP or IB exam results that the student self-reports. If the results of the math placement test contradict AP or IB scores, or if students wishes to take a different level of math than the placement test recommends, students are referred to math placement advisers for further consultation. The student makes a decision regarding which math class to start in from these discussions and is allowed to register for whichever math she wishes. Each math course is offered every quarter, allowing students flexibility in terms of starting and stopping the sequence. With our current first-year advising practices and policies, even if the math preparation of any given year of incoming freshmen does change, the course that the individual student is advised to take depends on her individual performance on a math placement exam and her individual preparation.

Over the last five years, roughly $70-80 \%$ of the first-year student population each year places into differential calculus of multivariable functions. The remaining $20-30 \%$ of the class typically places $\sim 10 \%$ into single variable integral calculus, and $\sim 10 \%$ into single variable differential calculus, with $\sim 3-5 \%$ inconclusive results and $~ 3-5 \%$ not taking the placement exam. If we look at the percentage of the overall student population testing into multivariable calculus we see that there has been an overall trend upwards in the level of preparation of students entering the school of engineering (Figure 3). A quick review of national trends shows that the number of students taking AP Calculus BC exam has more than doubled in the last 10 years (The College Board, 2016). It bears noting that the number of students testing into multivariable calculus over the past three years is roughly double the number of students coming in with enough credit to begin in multivariable calculus (Figure 3). This suggests that independent, university-offered summer placement exams may be crucial to the appropriate placement of the student, as well as knowledge of the overall student population distribution. Another interpretation of the data is that many students are choosing not to take the AP exam, or that our placement exam is easier and more students are testing higher than they should.

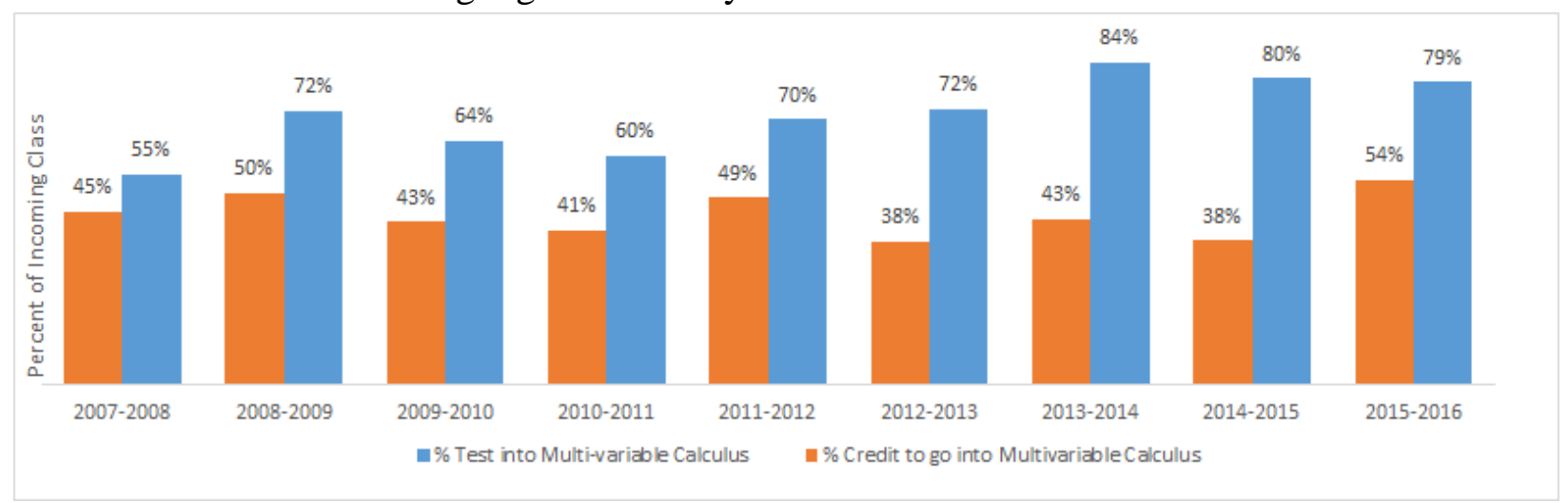

Figure 3 - Placement into Differential Calculus of Multivariable Functions by either AP/IB/transfer credit (orange) or the engineering school's summer placement test (blue). 
Additional analysis of the past two years of student math placement and outcomes in their respective math courses taken shows an example of the extent to which students followed the results of the school's math placement test and their resulting performance (Figure 4). Students were allowed to enroll in any math course, but arrows designate the subset of students who enrolled in the course for which they were recommended. Overall, $80 \%$ of students took the level of calculus that the math placement exam recommended them into, with $14 \%$ taking one or two levels lower than the exam recommended, $4.7 \%$ taking a level or two higher, and $1 \%$ with no record of taking one of these three math courses. Many first-year students want to retake math courses that they have already seen to help buffer them in their transition to college from high school. However, students also have an incentive to take a higher level of calculus than the placement exam recommends, as they are exempted from the preceding courses if they average a $\mathrm{C}$ or better in the higher level class.

Table 2 below shows the number of students placing into each level of calculus, the number taking each course, and the average and standard deviations of their grade in the course. No attempt was made to minimize variation in the rest of the student's course load, instructors teaching the course, or other variables which could affect course outcomes. In fact, it possible that students coming in with less math and testing into single variable calculus courses would also come in with less science preparation, and thus would carry a heavier academic load overall.

\begin{tabular}{|l|l|l|}
\hline $\begin{array}{l}\text { 66 placed into } \\
\text { Differential } \\
\text { Single Variable } \\
\text { Calculus }\end{array}$ & 44 took Differential Single Variable Calculus (rec level) & $2.7 \pm 1.1$ \\
\cline { 2 - 3 } & 17 took Integral Single Variable Calculus (+1 level) & $2.0 \pm 1.0$ \\
\hline $\begin{array}{l}\text { 64 placed into } \\
\begin{array}{l}\text { Integral Single } \\
\text { Variable } \\
\text { Calculus }\end{array}\end{array}$ & 10 took Differential Single Variable Calculus (-1 level) & $3.1 \pm 0.8$ \\
\cline { 2 - 3 } & 42 took Integral Single Variable Calculus (rec level) & $2.4 \pm 0.9$ \\
\cline { 2 - 3 } & 12 took Differential Multivariable Calculus (+1 level) & $2.7 \pm 0.9$ \\
\hline $\begin{array}{l}492 \text { placed into } \\
\text { Differential } \\
\text { Multivariable } \\
\text { Calculus }\end{array}$ & 13 took Differential Single Variable Calculus (-2 levels) & $3.5 \pm 0.4$ \\
\cline { 2 - 3 } & 65 took Integral Single Variable Calculus (-1 level) & $2.8 \pm 1.0$ \\
\cline { 2 - 3 } & 414 took Differential Multivariable Calculus (rec level) & $3.1 \pm 0.8$ \\
\hline
\end{tabular}

Table 2 - Recommendations of math placement exam and breakdown of students' actual math enrollment and associated average and standard deviation of resulting GPA (4.0 point scale).

Sixty-six students placed into differential single variable calculus, and 44 of them $\left(\sim^{2} / 3\right)$ took the recommended level and got an average GPA of $2.7 \pm 1.1$; the 17 students who took one level higher averaged $2.0 \pm 1.0$. Sixty-four students placed into integral single variable calculus, and 42 (roughly $2 / 3$ ) took the recommended course and average $2.4 \pm 0.9$; those 10 taking a level 
lower did better with a GPA of 3.1 \pm 0.8 , and those taking a level higher also did better averaging $2.7 \pm 0.9$. The vast majority of the students placed into to differential multivariable calculus (492) and $85 \%$ of students took the recommended course averaging a GPA of $3.1 \pm 0.8$. The remaining 65 students who took a level lower than recommended and took Integral single variable calculus averaged a GPA of $2.8 \pm 1.0$, almost totally overlapping with those that were recommended to take Integral single variable calculus in the first place $(2.7 \pm 0.9)$. Students who took two levels lower than their recommended multivariable calculus faired much better, averaging a $3.5 \pm 0.4$. It is unclear why student outcomes in integral single variable calculus are lower than they are in differential single variable or multivariable calculus. The advisers need to dig deeper into this issue, and potentially re-validate the math placement exam, which was originally created and validated twenty years ago.

\section{Engineering Analysis Curriculum, Advising Practices \& Outcomes}

Engineering analysis (EA) is a four-course sequence that covers several engineering-related topics. By design, engineering analysis was developed in the mid-1990s to create a single unified curriculum taught by engineering professors during the freshmen year, and this shift towards engineering courses to freshmen was largely successful. At the time, the preparation level of incoming students in math and physics was relatively uniform, and the curriculum was sufficiently advanced that the playing field was relatively even.

The first three quarters of the EA sequence are required for all engineering majors. EA1 introduces linear algebra and computational methods from an applications viewpoint; students are introduced to MATLAB and MATLAB programming to solve problems. This course is typically taken fall quarter of the first year. Some students either do not take EA1 in the fall, or have to repeat it. Since each EA course is offered the following quarter, these students take the "trailer section" in the winter quarter. EA2 introduces students to statics and is normally taken winter quarter of the first year. Students continue to use MATLAB to solve problems related to statics. EA3 introduces dynamic systems; the course teaches students how to model mechanical, electrical, thermal, hydraulic and chemical systems that are composed of elements. EA4 is differential equations with more engineering applications and examples and is usually taken fall quarter of sophomore year.

All first-year students, regardless of their level of math or physics preparation, are advised to take the first quarter of engineering analysis, EA1 (linear algebra), fall quarter. This model of placing all students into EA1 (linear algebra) in the fall, EA2 (statics) in the winter, EA3 (dynamics) in the spring is still followed today. A trailer section of EA1 is offered in the winter quarter, but typically accommodates only $10-15 \%$ of the class, and is intended for students who do not progress towards Engineering Analysis 2 (drop, withdrawal or grade of C- or lower fall quarter) or for students who transfer in from another school at the University during the winter quarter. No additional summer placement exams other than math are administered to determine 
if students are ready for the EA sequence, and in general, level of math or physics preparation is not considered unless a student comes in with credit for higher level mathematics such as linear algebra. Advisers typically do not reveal to first-year students that there is a trailer sequence; thus, the vast majority take EA1 fall quarter.

As a result, advice given to any student, even today, regarding engineering analysis is not really individualized; this is done simply because it has been the only option available to date. Students who have taken calculus-based physics (the core of EA2 and EA3) are tracked into the same class as those who have had algebra-based physics only, and those who have no physics background at all. An honors engineering analysis sections do exist for those students who come in with an exceptional level of math performance, however, this section is only roughly 50-60 students per year, and is currently only offered for EA1 and EA4, and not for EA2 and EA3. Preparation for the engineering analysis sequence would be comprised of a student's math (largely EA1 and EA4), physics (largely EA2 and EA3) and computer programming experience (all EA courses). Below, we consider only physics and math preparation and their impact on engineering analysis 2 and 3 outcomes. The analysis presented below is only a beginning of the steps that need to be taken to determine how student preparation is impacting success in EA. Student preparation in physics was examined by tabulating students' earned credits from AP/IB exams over the past nine years (Figure 4). Data show the number of students as a function of the overall class by year coming in with credit for either calculus-based mechanics or algebra-based mechanics. The biggest trend appears to be an increase in the number of students coming in with credit for calculus-based mechanics, a trend that perhaps reflects the same increase in the level of calculus preparation of students.

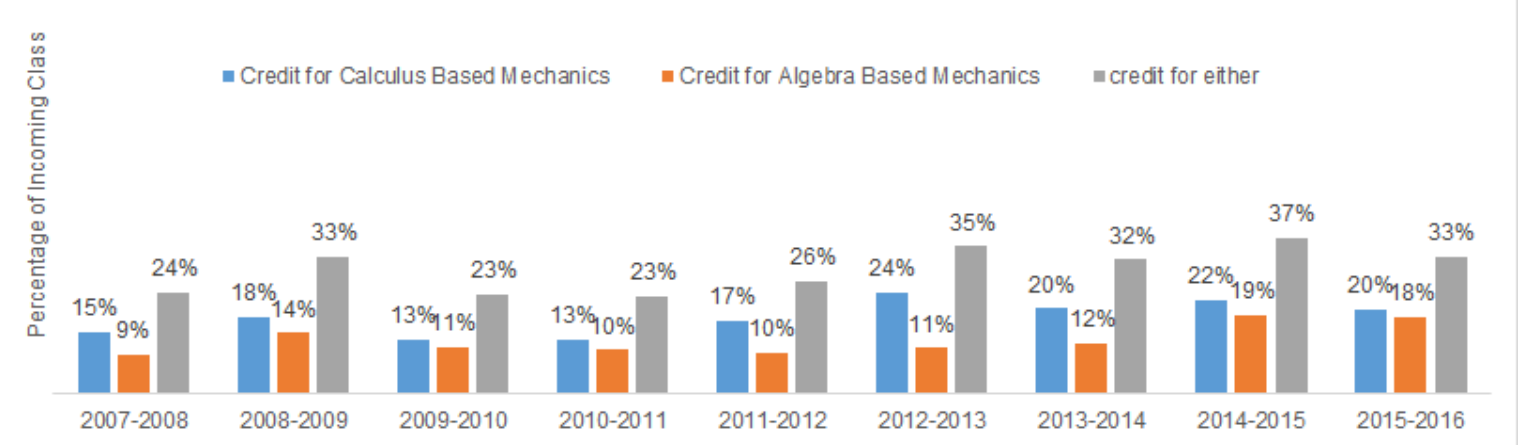

Figure 4 - Credit earned by students from either Physics B or Calculus Physics (Mechanics) placement exams or IB exams, or both as a percentage of the incoming class over 2007-2016

If we look at the number of students coming in with algebra-based mechanics and calculus-based mechanics, or both, as a percentage of the overall size of the class, there appears to be a trend upward over the past 9 years. (Please note that there are students who have credit for both the calculus-based and algebra-based mechanics exams; therefore, the "credit for either" is not 
always the sum of the calculus-based and the algebra-based exams in the chart above.) It is unclear if the students are more prepared, or if more of them are simply taking the exams. Furthermore, incoming credit data with regards to physics must be complemented by additional data from a summer administer physics placement test (which needs to be developed) to truly represent the overall preparation of the population. Nationally, the number of students taking either Physics AP exam has tripled in the last 10 years (The College Board, 2016).

There is no physics placement exam administered by the first-year advising office, and AP/IB credit has typically not yet been processed prior to the start of summer advising. As such, advisers use self-reported AP and IB scores (and ask students to report them even if they did not score high enough to receive credit) over the summer in order to assess the student's level of physics preparation. Post-advising, credit for algebra-based physics and calculus-based physics are posted by the Registrar's office. Roughly $45-50 \%$ of the incoming class self-reported taking either Physics C (calculus based mechanics) or Physics B (algebra based mechanics) exams, or both, in 2014-2015 and 2015-2016. Unfortunately, no data for Physics IB were collected due to an error in the reporting system. Also, some students may not have reported scores if they were too low to receive credit. Thus, there is potentially a larger number of students who took the physics advanced placement exams than the reported $45-50 \%$.

Table 3 shows the level of math and physics preparation of the 2015-2016 incoming class, reflecting the math they were placed into and their self-reporting of AP physics scores. The vast majority of students test into multivariable calculus, with half self-reporting an AP physics score and half not reporting an AP physics score. The students placing into a lower level of math (differential or integral single variable calculus) were much more likely not to have any selfreported AP physics score.

\begin{tabular}{|l|c|c|}
\hline & $\begin{array}{c}\text { No Self-reported AP } \\
\text { physics score }\end{array}$ & $\begin{array}{c}\text { With self-reported AP physics } \\
\text { score }\end{array}$ \\
\hline 1-Variable Calculus & $20.7 \%$ & $5.6 \%$ \\
\hline Multivariable Calculus & $35.6 \%$ & $36.7 \%$ \\
\hline
\end{tabular}

Table 3: Percentage of total student population with varying calculus and physics preparation for 2015-2016 incoming class

A more detailed, student-by-student analysis of outcomes by looking at students who failed to progress through the engineering analysis sequence in the 2015-2016 year was also performed. As all freshmen are advised to take Engineering Analysis 1 in the fall quarter, we do not look here at the number of students who took our advice--we assume that they all do, and this assumption is validated by class enrollment numbers. Analysis of progression from EA1 to EA2 is warranted, but has yet to be completed and thus is not reported here. To understand the effects 
of physics and math preparation in a course, we look specifically at progression from EA2 to EA3 in the spring. While the level of math preparation of the 83 students not progressing into EA3 (dynamics) from EA2 (statics) was roughly evenly split (half took multivariable calculus, half took single-variable calculus), the level of physics preparation was overwhelmingly lower (88\% had no or lower self-reported AP scores). This suggests that level of physics preparation plays a stronger role in non-progression from EA2 to EA3 than level of math preparation.

In addition to GPA and non-progression in EA, we have also looked at students placed on Academic Probation in either winter or spring quarter of their first year. Students whose GPA was less than 2.0 or who had two grades of D or lower were put on Academic Probation for at least one quarter. During that time, an academic standing committee decides if a student's improved performance in the quarter during which they are on probation warrants removal of that status. We have also looked at students who decided to transfer to other schools at the university during their first year (retention). While we have not explored all reasons that students leave engineering, we do know that poor grades in first-year courses are one factor in their decision. We do not have data here to determine if the student left only the school of engineering or left the university as a whole. We only report the existence of academic probationary status in the first-year quarter, or a transfer out of the school of engineering.

\begin{tabular}{|c|c|c|}
\hline $\begin{array}{c}\text { Transfer out or academic probation: } \\
\mathbf{1 3 . 7 \%} \text { of class }\end{array}$ & $\begin{array}{c}\text { No self-reported AP } \\
\text { physics score }\end{array}$ & $\begin{array}{c}\text { Self-reported AP } \\
\text { physics score }\end{array}$ \\
\hline Single Variable Calculus & $6.6 \%$ & $1.4 \%$ \\
\hline Multivariable Calculus & $4 \%$ & $1.7 \%$ \\
\hline
\end{tabular}

Table 4: Percent of total student population either transferring out of engineering or on academic probation in 2015-2016 incoming class as a function of calculus/physics preparation

Table 4 shows the outcomes for the different buckets of students. During the 2015-16 school year, a total of $13.7 \%$ of first-year students went on Academic Probation or transferred out of engineering. Of the $13.7 \%, 77 \%$ (10.6\% of the incoming class) did not self-report an AP physics score, while $23 \%$ did (3.1\% of the incoming class). Of the $13.7 \%$, 58\% (8\% of the incoming class) tested into single variable calculus (integral or differential) and 42\% (5.7\% of incoming class) tested into multivariable calculus (Table 3). Thus, there appears to be a stronger relationship between lack of physics preparation and going on either academic probation or transferring out of the engineering school, in proportions similar to what we saw in nonprogression from EA2 to EA3. However, math preparation does play a role, as roughly $21 \%$ of the class of 2015-2016 had both no self-reported AP physics score and tested into single variable integral or differential calculus, and these students account for roughly half of the students who go on academic probation as freshmen or leave the school of engineering. There appears to be a 
stronger relationship between physics preparation and interschool transfer/academic probation than math preparation.

\section{Conclusions and Next Steps}

This process of data analysis has revealed the importance of different kinds of data to the advising process, and has proven instrumental in provoking the first-year advisers to do further work. Below, we draw some broad conclusions, further work needed, and discuss changes which we will consider to our advising process.

- Using a summer engineering school-administered math placement exam instead of incoming credit to place students allows $\sim 30 \%$ of the student body to place into a higher level of math than using simply incoming credit in calculus. Analysis of two years of data (2014-2016) indicates that most incoming students (80\%) take the level of math recommended. Students placing into and taking multivariable calculus average a GPA of $3.1+/-0.8$; students placing into and taking differential single variable calculus average $2.7+/-1.1$, while those placing into and taking integral single variable calculus average $2.4+/-0.9$. Further investigation into reasons why students placing into lower levels of math do worse off than their peers placing into multivariable calculus is needed, and a new data set including information on other courses are taken concurrently needs to be created so that these factors can be investigated.

- The implementation of a physics placement exam appears to be an important change to the advising process. At this point, data from credit awarded does not sufficiently indicate the degree of preparation of the student; there may be a population of students who have several years of physics in high school but never take advanced placement exams; similarly, there may be students who have never taken physics in high school and as a result never took the exam. These two populations need to be separated out in order to better understand the reasons behind student outcomes. Data on non-progression and academic probation/interschool transfers for the 2015-2016 school year indicate that physics preparation may be equally if not more important than math preparation to firstyear student outcomes. The collection of self-reported data such as years of high school physics, level of high school physics, etc, can be an important refinement to help determine the overall level of student readiness in the interim before a physics placement test can be implemented.

- The engineering school as a whole may wish to look into changes to the Engineering Analysis sequence, particularly with regards to the increased math and science preparation observed over the last few years, along with trends in students who do not progress from statics to dynamics. Additionally, the creation of a section of engineering analysis targeting students with little or no physics preparation may be warranted; or the 
delay of EA1 for a quarter and adviser recommendations that these students take algebrabased physics fall quarter first year instead.

\section{References}

Freeman, RW \& Gentry, K, Changing the Advising Model, (2016, June) Changing the Advising Model Paper presented at 2016 ASEE Conference \& Exposition, New Orleans, Louisiana.

The College Board, AP Exam Volume Changes 2006-2016.

The College Board, 2016 AP Participation, 2016.

Robinson, M. (2003). Student enrollment in high school AP sciences and calculus: How does it correlate with STEM careers? Bulletin of Science, Technology \& Society, 23,265-273.

Brown JL, Halpin G and Halpin G. Relationship between High School Mathematical Achievement and Quantitative GPA. Higher Education Studies, Vol. 5, no. 6, 2015.

Hieb JL, Lyle KB, Ralston PAS, and Chariker J. Predicting performance in a first engineering calculus course: Implications for interventions. International Journal of Mathematical Education in Science and Technology, Vol. 46, no. 1, 2015.

Tyson W. Modeling engineering degree attainment using high school and college physics and calculus course taking and achievement. Journal of Engineering Education. Vol. 100, no. 4, 2011.

Veenstra CP, Dey EL, and Herrin GD. A model for freshman engineering retention. Advances in Engineering Education. Winter 2009.

Strayhorn TL. Modeling the determinants of college readiness for historically underrepresented students at 4-year colleges and universities: a national investigation. American Behavioral Scientist. Vol. 58(8), 2014.

Haag, S., Hubele, N., Garcia, A., \& McBeath, K. (2007). Engineering undergraduate attrition and contributing factors. International Journal of Engineering Education, 23, 929-940.

Meyer, M. and Marx, S. (2014), Engineering Dropouts: A Qualitative Examination of Why Undergraduates Leave Engineering. J. Eng. Educ., 103: 525-548.

Soulsby, E. (2005, June), Using 'Advising Contours' For Placement In First Year Quantitative Courses Paper presented at 2005 Annual Conference, Portland, Oregon. 
Suresh, R. (2006-2007) The relationship between barrier courses and persistence in engineering. Journal of College Student Retention, 8 (2), p. 215-39.

Marra, R. M., Rodgers, K. A., Shen, D. and Bogue, B. (2012), Leaving Engineering: A MultiYear Single Institution Study. Journal of Engineering Education, 101: 6-27.

Zola, M., \& Deess, E., \& Briller, V. (2002, June), Placement Tests As Predictors Of Student Achievement In Math, Chemistry, And English Paper presented at 2002 Annual Conference, Montreal, Canada. 